\title{
TOOTH DEVELOPMENT IN THE LIGHT OF CHEMOTHERAPY- INDUCED AGENESIS IN CANCER SURVIVORS
}

\author{
Anna Jodłowska, Lidia Postek-Stefańska \\ Department of Pediatric Dentistry, Medical University of Silesia, Katowice, Poland
}

\begin{abstract}
INTRODUCTION: Although the developmental model of permanent tooth is considered to be similar to the better understood formation of deciduous tooth, the duration of subsequent stages differs significantly, and it is difficult to determine. Various sources report that agenesis is a result of genetic abnormality or a developmental disturbance caused in initiation stage. However, it seems that complete damage to the germ, sometimes referred to as "aplasia", can occur during the entire early odontogenesis. Detailed antineoplastic treatment records and dental disturbances in children as a result of chemotherapy administration show the possibility to recognize not wellknown early tooth development.

ОвјестіVEs: An attempt to discover some unexplained facts about early tooth development based on the cases of chemotherapy-induced agenesis.

MATERIAL AND METhods: Thirty-eight cancer survivors presented for a check-up visit in the Pediatric Clinic fulfilled the study criteria. Clinical control and panoramic radiograph were performed to identify the developmental abnormalities of hard tissues. Medical records were also analyzed to distinguish the age and duration of the cytotoxic treatment. Thirty-one survivors showed long-term dental effects of therapy. Five participants had 13 teeth missing.

RESULTS: In the case of survivors with a lack of 6 teeth, germ-toxic drug administration was applied just before appositional growth. Individuals with 3 teeth missing started the therapy before or at the beginning of expected initiation stage. One patient with four second premolars missing was treated outside the early odontogenesis age period.

Conclusions: Detailed analysis revealed hypothesis that the total toxic damage to the dental developing tissues is likely to occur even at the most advanced stadium of early development. A longer duration of early odontogenesis is also possible. The duration of particular stages in tooth formation can be revised based on the dental examination of cancer survivors.
\end{abstract}

KEY WORDS: chemotherapy, tooth abnormalities, odontogenesis.

J Stoma 2021; 74, 1: 28-33

DOI: https://doi.org/10.5114/jos.2021.104695

\section{INTRODUCTION}

Research interests on tooth development are mainly focused on the aspect of protein secretion, subsequent mineralization, and regulatory mechanisms in late odon- togenesis, and are based on animal model $[1,2]$. Early stages of tooth formation are also investigated on rats or mice, by analyzing signaling molecules and genes expression in reciprocal interactions between epithelial and mesenchymal tissues [3]. Therefore, the duration of

\section{JOURNAL OF} STOMATOLOGY CZASOPISMO STOMATOLOGICZNE

AdDress For Correspondence: Anna Jodłowska, PhD, Department of Pediatric Dentistry, Medical University of Silesia, Katowice, Pl. Traugutta 2, 41-800 Zabrze, Poland, e-mail: wega25@poczta.onet.pl 
particular developmental stages in permanent dentition is difficult to determine. Although the developmental model of permanent tooth is considered to be similar to the better understood formation of deciduous tooth, the duration of subsequent stages differs significantly. Once the dental lamina is formed, the initiation of tooth development can occur due to interactions between epithelial and underlying mesenchymal tissue. The ectoderm thickens and then stimulates the surrounding neural crestderived mesenchyme to condensate around the epithelial bud (bud stage), after which, morphogenesis starts. The growing epithelium forms a cup-shaped structure resulting in enamel organ and dental papilla formation (cup stage). After intensive cellular proliferation, the epithelial part of the germ starts to resemble a bell-shaped structure (early bell stage). This is followed by morpho- and histodifferentiation, and the tooth crown reaches its final shape (late or advanced bell stage). This stage is completed by beginning of enamel and dentin apposition. Therefore, the bell stage is the most varied stage, with developmental cells changing from undifferentiated to the most specialized cells. During the late bell stage, the size of the tooth crown is also determined and subsequently, as a result of simultaneously proceeding amelo- and dentinogenesis, the crown formation starts [3-5].

As a result of secretion of different signaling molecules, cell interactions during tooth development are possible to occur. Transforming growth factor $\beta$ (TGF- $\beta$ ), fibroblast growth factor (FGF), and Hedgehog and Wnt families, regulate interactions between ectodermal and mesenchymal cells during the initiation, morphogenesis, and cell differentiation in a tooth germ. Independently of the signaling activity of numerous molecules, inhibitory factors and gene expression also take part in early and advanced odontogenesis [3-5]. However, the tooth formation can be disturbed via another pathway, not only through chemical substance suppression or gene mutations. For instance, cytotoxic drugs interfere with cell cycle, leading to the death of germinative elements or malfunction of more mature tissue components. There are many experimental animal studies reporting dental damage after vincristine, cyclophosphamide, or actinomycin $\mathrm{D}$ administration [6-8]. It is widely documented that agenesis, microdontia, taurodontism, disturbed root development or enamel opacities, and hypoplasia are diagnosed in children treated with multi-agent therapy [9-15]. The reported prevalence of hypodontia is estimated to be $7-77 \%$, depending on inclusion criteria $[10,13,14,16-18]$. Excluding the lack of third molars, which affects $20-35 \%$ of people, agenesis is reported in $1.6-9.6 \%$ of healthy population [19-21].

Some sources report that anodontia is a result of genetic abnormality or a developmental disturbance caused by environmental factor in the initiation stage. When endocrine, toxic, or hereditary agent appears during a succeeding bud stage, microdontia or macro- dontia can occur. An impairment at a later cup stage can induce germ division, leading to germination, germs fusion, extra cusps, or dens invaginatus. Complete damage to the germ is also not expected when it comes to appositional tooth development [20, 22, 23]. Agenesis is a term describing missing tooth and it is usually considered as a congenital process: a tooth failed to develop $[24,25]$. However, it seems that a complete damage to the germ during the entire early odontogenesis is possible. This phenomenon is sometimes called "aplasia". In order to verify whether the lack of the tooth is due to germ damage or it is planned genetic disturbance, more data about the duration of particular developmental stages are necessary. The duration of permanent tooth developmental stages susceptible to impairment is not well-known for evident reasons. The second need is to determine the exact time of possible harmful factor impact, which is usually difficult.

Anti-cancer treatment is an accurately recorded therapeutic procedure with detailed drug administration. Dental abnormalities are the long-term sequelae of such a therapy, if received at the developmental age. A thorough comparative research on the age during antineoplastic treatment and the resultant dental disturbances can contribute to understand the unknown details on tooth development.

\section{OBJECTIVES}

The study aimed to discover various unexplained facts about early tooth development based on the cases of chemotherapy-induced hypodontia.

\section{MATERIAL AND METHODS}

Thirty-eight cancer survivors presented for a checkup visit in the Pediatric Clinic were invited to undergo dental examination. They fulfilled the following inclusion criteria: age between 5 years and 18 years, anti-cancer therapy before the age of 10 , and at least 2 years after treatment completion. A total of 30 individuals had a solid tumor, and the remaining 8 patients were diagnosed with leukemia. All of them received chemotherapy. Four patients were treated with head radiotherapy and 27 participants required surgery. They reported to our outpatient dental clinic, on average, 5 years and 2 months after completing their anti-cancer therapy (minimum 2 years and 2 months - maximum 10 years and 11 months). The patients' legal guardians gave their written consent for their participation in the study. Since the examination was targeted at developmental abnormalities of hard tissues, clinical examination and panoramic radiograph were performed. Thirty-one survivors presented with long-term dental effects of therapy. Table 1 presents the study findings completed up till now. Young age of some participants did not allow for a final 
TABLE 1. The prevalence of dental anomalies in the study group

\begin{tabular}{|l|c|c|}
\hline Dental anomalies & Number of patients with disturbed teeth, $\boldsymbol{n}(\%)$ & Number of teeth affected \\
\hline Dental anomalies in total & $25(65.79)$ & 231 \\
\hline Agenesis or aplasia & $5(13.16)$ & 32 \\
\hline Microdontia & $12(31.58)$ & 60 \\
\hline Tooth reduction in size & $18(47.37)$ & 31 \\
\hline Root disturbances & $5(13.16)$ & 62 \\
\hline Enamel anomalies & $5(13.16)$ & 13 \\
\hline Taurodontism & $6(15.79)$ & 17 \\
\hline Other & $4(10.53)$ & 2 \\
\hline
\end{tabular}

TABLE 2. Characteristics of the hypodontia group

\begin{tabular}{|c|c|c|c|c|c|c|c|}
\hline $\begin{array}{l}\text { Patient (age at } \\
\text { examination in } \\
\text { years), Figure }\end{array}$ & $\begin{array}{l}\text { Teeth } \\
\text { missing }\end{array}$ & $\begin{array}{l}\text { Development } \\
\text { beginning } \\
\text { (age in months) }\end{array}$ & $\begin{array}{l}\text { Mineralization } \\
\text { beginning } \\
\text { (age in } \\
\text { months) }\end{array}$ & $\begin{array}{c}\text { Age at } \\
\text { start of } \\
\text { treatment } \\
\text { (months) }\end{array}$ & $\begin{array}{c}\text { Age at } \\
\text { treatment } \\
\text { completion } \\
\text { (months) }\end{array}$ & $\begin{array}{l}\text { Treatment } \\
\text { duration } \\
\text { (months) }\end{array}$ & $\begin{array}{l}\text { Other possible long- } \\
\text { term effects }\end{array}$ \\
\hline \multirow[t]{2}{*}{ J.M. (8.5), Figure 1} & 12,22 & $5-5.25$, in utero & $3-4(10-12)$ & 9 & 18 & 9 & \multirow{2}{*}{$\begin{array}{c}55,54,64,65,75,74,84 \\
85,16,26,36,46 \\
\text { - taurodontia }\end{array}$} \\
\hline & 37 & $8.5-9$ & $30-36$ & 9 & 18 & 9 & \\
\hline S.D. (7.5), Figure 4 & 37,47 & $8.5-9$ & $30-36$ & 28 & 38 & 10 & 17,27 - microdontia \\
\hline \multirow[t]{2}{*}{ K.R. (13), Figure 3} & 24 & 0 & $18-24$ & 24 & 45 & 21 & $\begin{array}{c}12,22,14,44,17,27 \\
\text { - reduction in size }\end{array}$ \\
\hline & 45 & $7.25-8$ & $24-30$ & 24 & 45 & 21 & $\begin{array}{l}35 \text { - root stunting; } \\
11 \text { teeth - DDE }\end{array}$ \\
\hline W.M. (9.5) & $15,25,35,45$ & $7.25-8$ & $24-30$ & 41 & 53 & 12 & \\
\hline C.A. (11.5), Figure 2 & 18,28 & $42-48$ & $84-120$ & 29 & 42 & 13 & $\begin{array}{c}15,25,35,45,27,37,47 \\
\text { - microdontia }\end{array}$ \\
\hline
\end{tabular}

assessment of potential disturbances, especially in terms of root formation. Based on panoramic radiographs, two independent examiners selected patients with missing teeth. Then, their medical history was analyzed, with special attention paid to the age and duration of cytotoxic treatment. The data obtained were compared with historical details concerning early permanent teeth formation presented in the literature [26]. An attempt was made to perform a thorough analysis of some developmental aspects in human odontogenesis.

\section{RESULTS}

The mean age at cancer diagnosis was 3 years and 2 months (range, 4 months -8 years and 6 months). Clinical and radiological examinations revealed hypodontia in 5 of $38(13.16 \%)$ cancer survivors included in the study. All of them received chemotherapy and no head radiotherapy was administered. Five individuals had 13 teeth missing: 2 lateral incisors, 1 first premolar, 5 second premolars, 3 second molars, and 2 third molars. Three of them had teeth with other dental abnormalities, such as microdontia, reduced crown size, and root stunting. Study results and details on teeth development are shown in Table 2. Only one survivor with 4 second premolars missing was treated outside early odontogenesis age period. In this patient, one-year late teeth eruption was reported. Three survivors with a lack of 6 teeth received toxic drugs just before appositional growth of hard dental tissues. Other 2 patients with 3 teeth missing started their therapy before or at the beginning of the expected initiation of odontogenesis. Detailed analysis revealed a hypothesis that the total toxic damage to the developing dental tissues was likely to occur even at the most advanced stage of early development. The second hypothesis was that a longer duration of early odontogenesis could also be possible.

\section{DISCUSSION}

Exposure to chemotherapy can temporarily result in an impairment of immature tissues. Once a chemotherapy cycle is completed, tooth development is usually continued. Post-treatment hypodontia is a symptom indicating total tissue damage. Chemotherapeutic agents are targeted at rapidly dividing cancer cells. The less 
a cell is differentiated, the greater probability of its death. Epithelial and mesenchymal tissues present an increased mitotic activity during early odontogenesis, and thereby they are more susceptible to cell cycle disturbance and subsequent apoptosis. Maturation of enamel and dentin producing cells occurs at the advanced bell stage. These cells change from presecretory preameloblasts and preodontoblasts to non-dividing secreting ameloand odontoblasts $[4,22,27]$. As demonstrated in many experimental studies, preodontoblasts were strongly affected by high-dose cytotoxic drug administration, but the effect was temporary, followed by rapid cells regeneration. These new pulp-derived odontoblasts produced regular dentin as opposed to disturbed and highly differentiated odontoblasts with impaired dentin matrix secretion $[6,28]$. By contrast, amelo- and odontoblasts are resistant to impairment due to their maturity, even though they can exhibit chemotherapy-induced changes in secretory activity. It has been demonstrated in polarized light microscopy that intravenously administered chemotherapy resulted in the presence of incremental lines in the dentine of deciduous molars. These spaces of disturbed matrix secretion corresponded with particular drugs cycles $[25,29]$. When it comes to undifferentiated tissues, death due to cessation of cell division is more probable. In a previous author's report on a patient who had all of the first premolars peg-shaped, histological findings revealed a decreased number of dentin producing cells after chemotherapy, which was initiated at the age of 12 months. The cytotoxic therapy overlapped with an early odontogenesis of these teeth, supposedly during early bell stage. The fact that chemotherapy was administered just before mineralization indicates a relatively short duration of the bell stage, especially that the second premolars, which developed nearly 8 months later, were left undisturbed. This could suggest that the tooth germ is resistant to environmental impairment during the very early development. The patient started his therapy approximately 4 months after the expected initiation of the formation of second premolars. The 12-month treatment strongly overlapped with the entire period of expected early odontogenesis of well-developed second premolars [30]. Consequently, the size and shape of a tooth would have to be determined in a short time of the final period of bell stage. These two features of tooth formation are believed to be initially dependent on the presence of primary enamel knot created at the bud stage, and secondary or tertiary (in case of molar tooth germs) enamel knots appearing within the late cup and early bell stages [5, 21]. Enamel knot is the signaling center of non-dividing cells, which is believed to control proliferation of epithelial germ cells from the bud to bell stage. The non-dividing cells can be considered as highly specialized, and therefore resistant to toxic impairment. Secondary enamel knot (SEK) determines cusp pattern of tooth. Final maturation of odontoblasts starts from the tips of cusps after

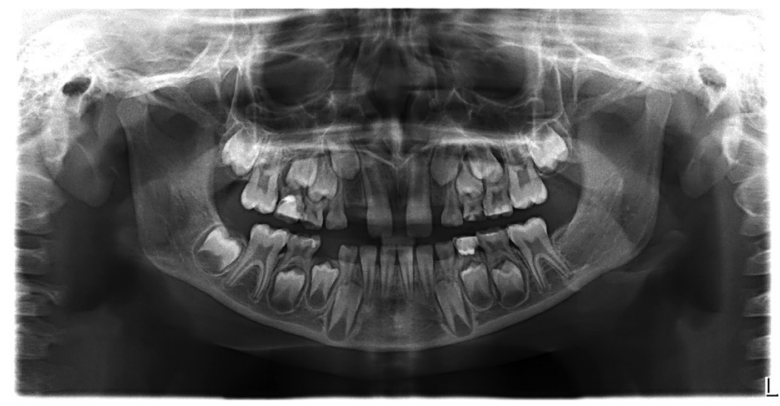

FIGURE 1. Panoramic radiograph of patient J.M. (Table 2). Missing teeth: 12, 22, 37

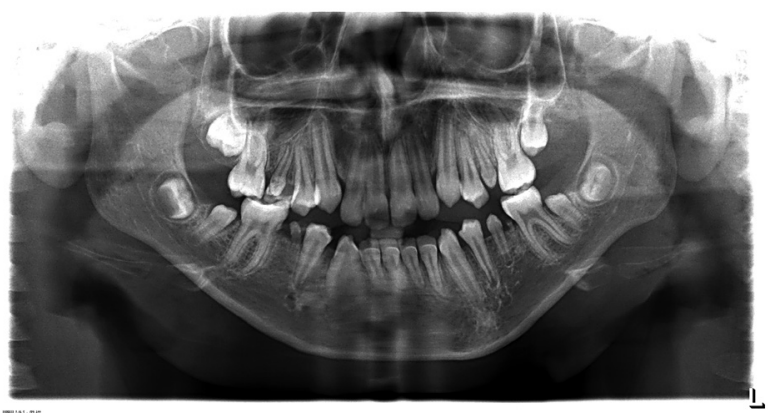

FIGURE 2. Panoramic radiograph of patient C.A. (Table 2). Missing teeth: 18, 28

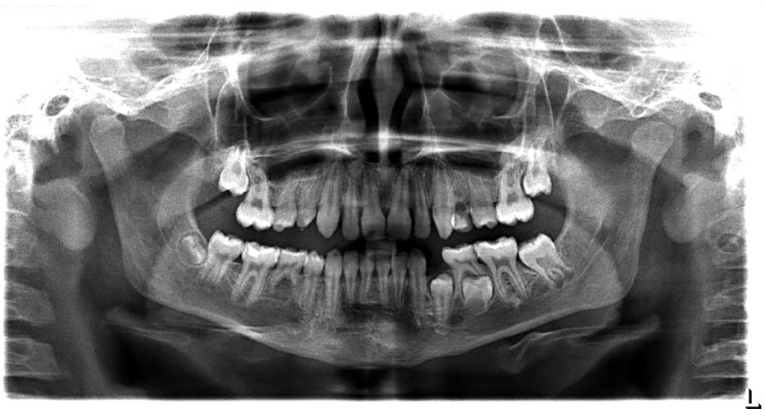

FIGURE 3. Panoramic radiograph of patient K.R. (Table 2). Missing teeth: 24,45

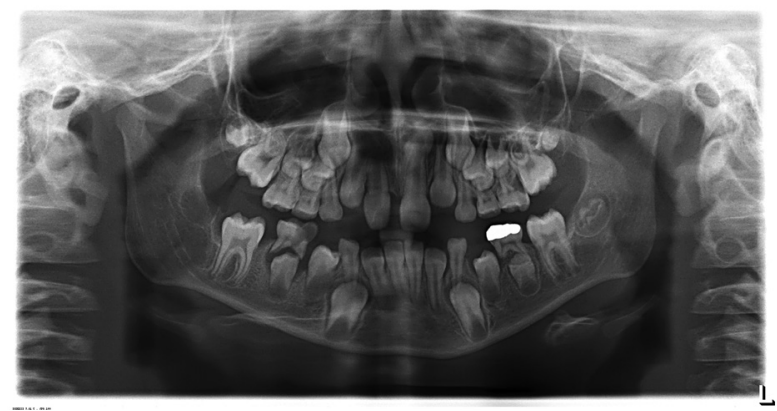

FIGURE 4. Panoramic radiograph of patient S.D. (Table 2). Missing teeth: 37,47

SEK cells secrete appropriate signaling substances [5]. It seems that the impairment of signaling activity of 
enamel knot's cells may be correlated with arrested differentiation of odontoblasts, and subsequently damage dentin matrix secretion and cessation of enamel formation. This could be the possible mechanism of the total tissue damage at the advanced bell period.

Only one investigated patient had no lateral incisors, second premolars, or third molars missing. These teeth are characterized as relatively frequently missing teeth in general population $[21,22]$. But even third molars, sometimes considered to be excluded from the study reports, are found to be more frequently missing teeth in cancer survivors compared to healthy subjects [16, 24]. Depending on the age at the start of treatment, all of these groups of teeth are also exposed to the risk of cytotoxic damage. However, in the present report, some of these anomalies were probably not side effects of therapies. Patient with maxillary lateral incisors missing had agenesis of the same deciduous teeth. However, the lack of these teeth may be due to treatment as all of the deciduous molars were taurodontal. Even though permanent first molars were also taurodontal, this was an individual developmental feature of the study participant rather than post-treatment pathology, considering the time of cytotoxic therapy (Figure 1). Similarly, a girl with the lack of 4 second premolars began the therapy at least 11 months after the onset of mineralization. However, the fact of one-year late eruption in this girl could have been a circumstance indicating treatment impact. Another patient (Figure 2) presented with missing maxillary third molars, all of the second premolars, and three second molars microdontal, in whom the therapy was administered at the expected time of early odontogenesis of all teeth reduced in size. The therapeutic etiology of microdontia in this survivor is undeniable. Similar case was presented in another study, where the therapy started shortly before mineralization. However, when it comes to third molars missing, it seems that the formation of maxillary molars could precede the development of mandibular antagonists and therefore, these teeth could fail to develop. Or else, according to the above assumption regarding first period of early odontogenesis relatively resistant to total tissue damage, the mandibular molars could develop earlier than their maxillary counterparts and earlier than commonly accepted.

The lack of remaining one first premolar, one second premolar, and three second molars resulted from anti-cancer treatment was probably due to the damage of another teeth from the same developmental groups. A strong correlation between simultaneously occurring hypodontia and microdontia in cancer survivors is often reported $[16,20]$. Considering the age at therapy in the investigated patient with right mandibular second premolar missing, it appears that the toxic treatment started shortly before mineralization. Other causes of the damage due to severely late development of the opposite mandibular second premolar in this participant were eliminated (Figure 3). The above-described patient with the lack of 2 lateral incisors (Figure 1) has also one left mandibular second molar missing, but the anti-cancer drug administration took place before or at the beginning of early odontogenesis. The alveolar bone crypt in the place of the expected tooth seems to be welldefined even after many years. If the observation is correct, the conclusion is difficult to determine. Germ damage could occur at a stage, in which SEK determining tooth shape and size were well formed. What is interesting, the size of alveolar bone crypt in cases of microdontal teeth is adjusted to their reduced size, but the crypt in the place of missing tooth germ in the analyzed survivor was greater and corresponds to the size of physiologically developed future tooth crown. How to explain this phenomenon? Treatment duration lasted for only 9 months. Does the initiation of tooth development occur earlier than reported in the literature? And how does it correspond with the fact that the treatment overlapped with the final period of expected early tooth development in the next patient with two mandibular second molars missing (Figure 4)? This survivor exhibited microdontia of two maxillary second molars. It relates to an observation that the germs of upper second molars could have appeared earlier than their corresponding mandibular counterparts, considering that the development of particular teeth may be early or late. It could be that they appeared to be more resistant to the total damage due to their more advanced development. Based on the last case, it may be concluded that the maturation of dental tissue producing cells occurs earlier than previously believed. The same observation concerns the study participant with the lack of one maxillary first premolar and other two first premolars slightly reduced in size, who started treatment just before or at the expected beginning of mineralization. Do we know everything about tooth formation? Does the fact that an abnormality sometimes concerns only one tooth of the same developmental group and indicate that there is only a short period of odontogenesis with an increased risk for the severe germ injury?

The above-described hypotheses should be formulated carefully. There are significant differences in the duration of development and time of teeth eruption. However, it is difficult to agree with the opinion that the lack of a tooth originate from the initiation stage only, in which agenesis can clearly occur. However, if the damage of a previously formed tissues (so-called "aplasia") is considered, a total damage is possible, probably even at the advanced bell stage. A cross-check with similar observations is needed. Research results are usually limited to a comment that chemotherapy can variously alter the development of different teeth, depending on the treatment conditions. Wider and thorough analysis of chemotherapy-induced abnormal dental development is required. A small study cohort is the main constraint in a reliable interpretation of the long-term adverse effects of anti-cancer treatment. 


\section{CONCLUSIONS}

Tooth germ seems to be susceptible to complete cytotoxic damage during the entire period of early development. Hypodontia results not only from the lack of germ formation, but it can be the sequel of total tissue damage or cessation of development of non-mineralized dental structures. The duration of particular developmental stages in tooth formation can be revised based on the results of long-term treatment effects in cancer survivors.

\section{ACKNOWLEDGMENTS}

This work was supported by statutory sources KNW$1-016 / \mathrm{K} / 9 / \mathrm{K}$ from the Medical University of Silesia. There are no conflicts of interest to declare.

\section{CONFLICT OF INTEREST}

The authors declare no potential conflicts of interest with respect to the research, authorship, and/or publication of this article.

\section{References}

1. Guo J, Lyaruu DM, Takano Y, Gibson CW, DenBesten TK, Bronckers ALJJ. Amelogenins as potential buffers during secretory-stage amelogenesis. J Dent Res 2015; 94: 412-420.

2. Zheng L, Ehardt L, McAlpin B, et al. The tick tock of odontogenesis. Exp Cell Res 2014; 325: 83-89.

3. Thesleff I. Epithelial-mesenchymal signalling regulating tooth morphogenesis. J Cell Sci 2003; 116: 1647-1648.

4. Kwon HJE, Jiang R. Development of tooth. Ref Mod Biomed Sci 2018. DOI: 10.1016/B978-0-12-801238-3.64113-2.

5. Thesleff I, Keränen S, Jernvall J. Enamel knots as signaling centers linking tooth morphogenesis and odontoblast differentiation. Adv Dent Res 2001; 15: 14-18.

6. Lyaruu DM, van Duin MA, Bervoets TJM, Wöltgens JH, Bronckers AL. Effects of actinomycin D on developing hamster molar tooth germs in vitro. Eur J Oral Sci 1997; 105: 52-58.

7. Takuma S, Sawada T, Yama S, Yanagisawa T. Ultrastructural changes in the cementoblasts of rat molars after injection of vincristine. J Dent Res 1984; 63: 1108-1115.

8. Vahlsig HL, Kim SK, Feringa ER. Cyclophosphamide-induced abnormalities in the incisors of the rat. J Dent Res 1977; 56: 809-816.

9. Jodłowska A, Sobol-Milejska G, Postek-Stefańska L. A critical look at prevalence assessment of dental abnormalities after chemotherapy. Clinical research. J Stoma 2019; 72: 95-105.

10. Krasuska-SławińskaE,BrożynaA,Dembowska-BagińskaB,OlczakKowalczyk D. Antineoplastic chemotherapy and congenital tooth abnormalities in children and adolescents. Contemp Oncol 2016; 20: 394-401.

11. Proc P, Szczepańska J, Skiba A, Zubowska M, Fendler W, Młynarski W. Dental anomalies as late adverse effect among young children treated for cancer. Cancer Res Treat 2016; 48: 658-667.

12. Gawade PL, Hudson MM, Kaste SC, et al. A systematic review of dental late effects in survivors of childhood cancer. Pediatr Blood Cancer 2014; 61: 407-416.

13. Avsar A, Darka O, Pinarli G. Long-term effects of chemotherapy on caries formation, dental development and salivary factors in childhood cancer survivors. Oral Surg Oral Med Oral Pathol Oral Radiol Endod 2007; 104: 781-789.
14. Marec-Berard P, Chaux-Bodard AG, Lagrange H, Gourmet R, Bergeron C. Long-term effects of chemotherapy on dental status in children treated for nephroblastoma. Pediatr Hematol 2005; 22: 581-588.

15. Kaste SC, Hopkins KP, Jenkins JJ. Abnormal odontogenesis in children treated with radiation and chemotherapy: imaging findings. AJR Am J Roentgenol 1994; 162: 1407-1411.

16. Hölttä P, Alaluusua S, Saarinen-Pihkala UM, Peltola J, Hovi L. Agenesis and microdontia of permanent teeth as late adverse effects after stem cell transplantation in young children. Cancer 2005; 103: 181-190.

17. Oguz A, Cetiner S, Karadeniz C, Alpaslan G, Alpaslan C, Pinarli G. Long-term effects of chemotherapy on orodental structures in children with non-Hodgkin's lymphoma. Eur J Oral Sci 2004; 112: 8-11.

18. Kaste SC, Hopkins KP, Bowman LC, Santana VM. Dental abnormalities in children treated for neuroblastoma. Med Pediatr Oncol 1998; 30: 22-27.

19. Baczyk-Łopuch O, Hille A, Loster W. Estimation of hypodontia prevalence in patients treated at the Orthodontic Jagiellonian University Dental Clinic in Cracow. J Stoma 2014; 67: 624-636.

20. Pedersen LB, Clausen N, Schroder H, Schmidt M, Poulsen S. Microdontia and hypodontia of premolars and permanent molars in childhood cancer survivors after chemotherapy. Int J Paediatr Dent 2012; 22: 239-243.

21. Tucker A, Sharpe P. The cutting-edge of mammalian development; how the embryo makes teeth. Nat Rev Genet 2004; 5: 499-508.

22. Bath-Balogh M, Fehrenbach MJ. Illustrated dental embryology, histology, and anatomy. $3^{\text {rd }}$ ed. St. Louis, MO: Elsevier Saunders; 2011.

23. Avery JK, Chiego DJ. Essentials of oral histology and embryology. A clinical approach. $3^{\text {rd }}$ ed. Mosby Elsevier; 2006.

24. Kang CM, Hahn SM, Kim HS, et al. Clinical risk factors influencing dental developmental disturbances in childhood cancer survivors. Cancer Res Treat 2018; 50: 926-935.

25. Maguire A, Craft AW, Evans RGB, et al. The long-term effects of treatment on the dental condition of children surviving malignant disease. Cancer 1987; 60: 2570-2575.

26. Cameron AC, Widmer RP. Handbook of Pediatric Dentistry. $3^{\text {rd }}$ ed. Mosby Elsevier; 2008.

27. Couve E, Osorio R, Schmachtenberg O. The amazing odontoblast: activity, autophagy, and aging. J Dent Res 2013; 92: 765-772.

28. Nogueira TO, Stene T, Koppang HS. Long-term effects of colchicine on dentinogenesis in rat incisors. Eur J Oral Sci 1980; 88: 15-21.

29. Macleod RI, Welbury RR, Soames JV. Effects of cytotoxic chemotherapy on dental development. J R Soc Med 1987; 80: 207-209.

30. Jodłowska A, Pająk J, Postek-Stefańska L. Microdontia after chemotherapy in a patient treated for neuroblastoma: histopathological findings. Dent Med Probl 2018; 55: 343-349. 